www.czasopisma.marszalek.com.pl/pl/10-15804/npw

\author{
ЗЕЙНАБ БАХТУРИдЗЕ \\ Гуманитарный институт Санкт-Петербургского \\ политехнического университета Петра Великого \\ НАТАЛИЯ ВАСИЛЬЕВА \\ Санкт-Петербургский государственный университет
}

\title{
Гендерные аспекты подготовки специалиста-международника
}

\section{Гендерные аспекты подготовки специалиста-международника}

\section{Аннотачия}

В данной статье рассмотрены особенности влияния гендерного фактора на обучение студентов по специальности международные отношения и международная регионалистика. Актуальность исследования обусловлена, прежде всего, современной феминизацией университетского образования, а также ростом профессионального интереса женщин к сфере международных отношений. Научная и образовательная деятельность современных университетов является чрезвычайно важной в условиях развития «общества знаний», для эффективного функционирования которого необходимо активно привлекать интеллектуальный капитал, как мужчин, так и женщин. Поэтому университеты должны стать не только «фабриками знаний», но и формировать гендерную культуру студенчества. Проблема гендерных характеристик научной и образовательной среды университетов является крайне значимой. Авторы раскрывают тему, с одной стороны, на основе современных гендерных исследований в области международных отношений, как российских, так и западных ученых, а с другой стороны, на основе анализа конкретных данных о феминизации образовательных программ по международной тематике россий- 
ских университетов в контексте перспектив выстраивания гендерного паритета в практике международных отношений и мировой политики.

Ключевые слова: гендерные исследования, феминизация университетского образования, международные отношения, общество знаний, интеллектуальный капитал, гендерная культура, Российская Федерация

\section{Gender aspects of training a specialist in international affairs}

\section{Abstract}

The article discusses the specificity of the influence of the gender factor on the education of students in the fields of international relations and international regional studies. The topicality of the research results mainly from the contemporary feminization of higher education, as well as the growing professional interest of women in international relations. The research and teaching activity of modern universities is extremely important in the context of the development of the "knowledge society", for the effective functioning of which it is necessary to actively engage the intellectual capital of both men and women. Therefore, universities should not only become "factories of knowledge", but also shape the gender culture of students. The problem of the gender characteristics of the scientific and educational community of universities is extremely important. The authors present the topic on the one hand on the basis of contemporary gender studies in the field of international relations, both Russian and Western scientists, and on the other - on the basis of the analysis of specific data on the feminization of study programs in the field of international subjects of Russian universities in the context of the perspectives of building gender parity in practice international relations and world politics.

Keywords: gender studies, feminization of university education, international relations, knowledge society, intellectual capital, gender culture, Russian Federation

\section{Введение}

В условиях формирования «общества знаний» (К обществам знания: сфера образования. При этом важно подчеркнуть, что качественные характеристики университетского образования во многом определяются гендерным фактором, а именно меняющимся статусом женщины в современном образовательном процессе. Во-первых, значительно 
возрастает количество девушек-студенток, как в мире в целом, так и в российских университетах, во-вторых, значительно выросло число женщин-преподавателей, а потому возник интерес к комплексу проблем, которые определяются как гендерные проблемы в системе университетской подготовки специалистов, в частности, в сфере международных отношений. В основе гендерной проблематики лежат социально и культурно детерминированные различия в поведении и статусных позициях женщин и мужчин, а также пути достижения гендерного паритета в политической и социально-экономической жизни современного общества. Наряду с термином «гендер» распространено понятие «феминизм», но термином «феминизм» определяются сугубо женские социально-экономические проблемы общества.

Гендерная тематика охватывает как социально-политические и экономические роли женщин, так и мужчин, акцентируя внимание на анализе структур власти, организации социальных и культурных институтов, моделей идеологического контроля в современных обществах. В современной международной практике термин «гендер» стал одним из наиболее употребляемых практически во все международных правовых документах $\mathrm{OOH}$ и других международных организаций. С середины 1970-х годов Организация Объединенных Наций и другие международные учреждения стали уделять внимание проблемам гендерного равенства. В 1975 году была проведена первая Всемирная конференция ООН по положению женщин, что дало толчок к разработке исследовательских тем по гендерной и феминистской тематике. Например, ассоциация международных исследований (ISA) (ISA: The International Studies Association, 2021) ввела специальную награду для пишущих по гендерной тематике в контексте международных отношений.

Гендерные исследования, которые проводились в последние десятилетия российскими обществоведами, способствовали корректировке законодательной, управленческой, информационно-образовательной политики государства. Значимость гендерных исследований состоит в том, что дается целостный взгляд на мир посредством междисциплинарного анализа, что позволяет комплексно подойти к практической реализации принципа гендерного паритета в современном социуме. 
Касательно сферы университетского образования нужно отметить, что формирование начал гендерной культуры способствует развитию у студентов навыков, необходимых для толерантного и взаимовыгодного профессионального роста после окончания обучения и выхода на первые ступени карьерной лестницы (Агамова, Аллахвердян, 2021).

\section{Обзор литературы}

К гендерным проблемам в последние годы обратились многие западные и российские ученые. Например, американская исследовательница Дж. Мертус пишет о значимости обучения гендерному анализу как педагогическому инструменту в ходе преподавания теории международных отношений (Mertus, 2007). В центре внимания российской исследовательницы международных отношений Е.Б. Шестопал оказались вопросы женского лидерства (Шестопал, 2002). В свою очередь Е.А. Здравомыслова и А.А. Темкина пишут об адаптации западных гендерных исследований к российской проблематике (Здравомыслова, Темкина, 1999). Западный политолог Дж. Скотт большое внимание уделила проблеме употребления понятия «гендер» в историческом познании (Scott, 1986). Анализ такой важной проблемы, как гендерные проблемы международных отношений, освещалась в работах С.М.Виноградовой и Н.А.Васильевой (Виноградова, Васильева, 2013). Западная исследовательница феминизма Дж. Стинс посвятила многие свои работы проблематике международных отношений (Steans, 1998). Президент Американской ассоциации международных исследований Дж. Энн Тикнер и Дж. Тру рассматривают гендерные проблемы и их исследования в исторической ретроспективе за прошедшие 100 лет, акцентируя внимание на влиянии гендерного фактора на современные международные отношения и мировую политику (Tickner, True, 2018).

\section{Постановка задачи}

Авторы данной статьи видят необходимость формирования гендерной культуры как одну из важнейших задач в российском образовательном процессе, как неотъемлемую часть гуманизации университетской 
образовательной среды. Актуальность темы во многом связана с той ролью, которую играют в современном университетском образовании женщины. Кроме того, необходимо проанализировать карьерные возможности девушек-студенток в профессиях, связанных с международными отношениями. Это важно исследовать, так как, с одной стороны, происходит феминизация высшего образования в сфере международных отношений, а с другой стороны, консервативный гендерный подход сохраняется в структурах российских внешнеполитических ведомств и международных организациях. Однако сохранение привилегированного положения мужчин в этих областях деятельности может негативно сказаться на решении амбициозных планов российского руководства по прорыву в «цифровую экономику» и в целом по использованию достижений четвертой научно-технологической революции. Так, например, в США женщин рассматривают в качестве «дополнительного ресурса» ускорения развития научно-технического прогресса и резерва руководящих кадров в сфере науки, государственного управления и международных отношений. Традиционно возглавляют представительство США в $\mathrm{OOH}$ женщины, что для российской внешней политики пока недостижимо.

Очевидным является факт, что развитие демократии и гуманизма в общественных отношениях невозможно без гендерного равенства, что означает учет прав, как мужчин, так и женщин. Поэтому гендерная проблематика должна стать важной частью воспитательного и образовательного процесса в российских университетах. Современные требования к подготовке будущих специалистов нашли отражение в Законе РФ «Об образовании» (Федеральный закон от 29.12.2012). Особо нужно подчеркнуть, что формирующееся «общество знаний» требует от современных специалистов умения быть «креативным классом», что означает способность генерировать и реализовывать инновации во всех сферах общественной жизни. Поэтому возрастают требования к университетам, как «фабрикам знаний», где нужно особое внимание уделить подготовке специалистов, способных усвоить новые профессионально значимые компетенции с учетом изменений гендерного соотношения в структуре трудовых ресурсов. Поэтому в данной статье и ставится задача определения роли гендерных 
факторов в университетском образовании при подготовке специалистов в области международных отношений.

\section{Методы исследования}

Гендерные исследования методологически связаны с развитием постмодернизма в конце XX века. Провозглашается идея «ацентризма», что означает принципиальное отрицание каких-либо привилегированных «центров» доминирования, в частности, человеческого рода - в живом и неживом мирах, западных стран - в мировой политике, мужского пола - над женским полом. Особенно глубоко эти темы стали прорабатываться в постпозитивистских исследованиях социокультурных отношений, в частности, в рамках феминистских и гендерных теорий международных отношений (Egboh, Aniche, 2011). Гендерные исследования изначально методологически были связаны с основными направлениями в философии, социологии, психологии и педагогике, что и определило их междисциплинарный характер. Именно в рамках гендерных исследований методологически было проведено разделение биологического (понятие «пол»), что предполагает изучение анатомо-биологических особенностей и социального (гендер), что включает в предмет изучения социокультурный контекст. Таким образом, в процесс университетского обучения постепенно стал входить компонент, связанный с новым методологическим подходом при рассмотрении межличностных отношений студентов, где акцент делается на формирование гендерной культуры. Как отмечает Дж.Скотт, в отличие от термина «пол» и термина «род», термин «гендер», не снимая и не отрицая половых различий, делает упор на те социальные особенности женщин и мужчин, которые, в конечном счете, и определяют своеобразность их поведения (Scott, 1986).

По сути, введение понятия «гендер» в научный оборот не только дополнило, но и, в большей мере, изменило теоретико-методологическую основу исследований международных отношений, так как значительно расширило круг анализируемых проблем и комплекс подходов, их исследующих. По мнению Дж. Мертос, теория международных отношений значительно идейно обогатилась благодаря 
включению гендерного подхода при анализе международных отношений и мировой политики. Поэтому автор справедливо делает вывод, что как феминизм, так и гендерные исследования вносят в область изучения международных отношений вклад, как в методологию, так и в критический анализ перспектив развития глобального социума. Поэтому столь важно включать эти исследования в университетское образование (Mertus, 2007).

В методологическом плане гендерный подход к изучению международных отношений позволил по-новому, с учетом изменившихся в XXI веке научно-технологических и социально-экономических условий, взглянуть на изменение статусно-ролевых позиций женщин и мужчин в развивающемся «обществе знаний», где на первый план выходит ценность интеллектуального капитала, не имеющего половых характеристик. В этом контексте мысль западного исследователя Ж. Тру о том, что традиционно ориентированная на мужское начало («маскулинная теория») практика международных отношений под воздействием гендерных подходов может приобрести новые формы (True, 2001). В современных условиях женщины овладевают теми видами профессиональной деятельности, которые считались сугубо мужскими и это уже устойчивая тенденция. Организатор глобальной компании по производству чипов для электронных устройств американка В.Дай считает, что это просто миф о неспособности женщин столь же успешно, как и мужчин, заниматься наукой, технологиями, математикой и пр. (Dai, 2012).

\section{Исследование}

Формирование навыков гендерной культуры должно стать органической частью общего процесса подготовки специалиста-международника, потому что именно от этой составляющей будет зависеть такие важные параметры деятельности выпускника, как межличностное взаимодействие в трудовом коллективе, прагматичное построение схемы продвижения по карьерной лестнице и пр. Нельзя не согласиться с И.И. Лысовой, что поло-ролевой подход в профессиональном образовании, учитывающий лишь особенности биологического пола, при котором 
декларировалась половая дифференциация, сейчас рассматривается не только как устаревший, но и как негуманный (Лысова, 2009).

Однако в этом вопросе есть и ряд дискуссионных моментов. Некоторые авторы считают, что половые различия могут иметь и важное социально-культурное значение. Так, например, в западной феминистской литературе часто используется теория С. Руддик, согласно которой можно говорить о так называемом «материнском мышлении» (maternity thinking). Основной характеристикой этого типа мышления является негативное отношение женщин-матерей к насилию и войнам, а потому женщины более способны к превентивной дипломатии и миротворчеству. Согласно С. Руддик, «материнское мышление» в своей основе строится на инстинкте сохранения жизни, что в итоге и способствует формированию концептуальных позиций отрицания насилия и сохранения мира (Ruddick, 1995).

В 2015 году в ходе проведения круглого стола министров Экономического и Социального Совета ООН (ЭКОСОС) по теме «Ответственность за достижение фактического равенства женщин и девочек» возникли дискуссионные темы, которые легли в основу новых задач $\mathrm{OOH} \mathrm{к} 2030$ году по гендерной тематике (Ответственность за достижение фактического равенства женщин и девочек, 2015). Так, например, отмечалось, что необходимо глубже осмыслить понятия «различие», «неравноправие», «разница поведения», «ассоциированное с полом поведение», «дискриминация на основании пола», «сексизм» и пр. Очевиден тот факт, что в гендерных исследованиях научными объектами являются в равной степени, как мужчины, так и женщины, а значит нужно признать наличие гендерного фактора во всех социальных процессах. К сожалению, гендерный состав международных организаций и характер международного экономического управления показывает приоритет мужского начала, что не способствует эффективности их функционирования. Позитивные изменения в этом вопросе наметились в ООН. В соответствии с программой «Общесистемная стратегия Организации Объединенных Наций по обеспечению гендерного паритета» (The United Nations' system-wide strategy on gender parity), была разработана дорожная карта для достижения паритета на высших 
уровнях руководства организации к 2021 году и по всем направлениям к 2028 году (System-wide strategy on gender parity, 2021).

В этой связи важно отметить инициативу Организации объединенных наций по разработке глобальных гендерных показателей. Индекс развития с учетом гендерного фактора (ИРГФ) и Показатель расширения возможностей женщин (ПРВЖ) были впервые рассчитаны перед Четвертой Всемирной конференцией по положению женщин (Пекин, 1995). Индекс гендерного неравенства (ИГН) включает в себя: уровень образования, участие в экономической и политической жизни, вопросы здравоохранения с женской спецификой, многоплановость неравенства на национальном уровне (Новаторские решения в области измерения неравенства и бедности). К сожалению, одним из самых низких показателей был показатель уровня образования, что негативно отражается на возможности женщин войти в образовательное пространство информационного общества. Образованные женщины имеют больше шансов получить удовлетворяющую их работу, участвовать в политической жизни, заботиться о своем здоровье и здоровье своей семьи и пр. Фактически образование создает условие для включения женщины в глобальное «пространство маскулинности», но пока «женский сегмент» этого пространства крайне ограничен, хотя «женщины и составляют более половины населения Земли и рабочей силы, однако они занимают менее чем $29 \%$ руководящих постов в глобальной экономике (Виноградова, Дунаева, Зиатдинов, 2017).

К сожалению, в современной экономике знаний многие женщины сталкиваются с проблемой продвижения, получившей название «стеклянного потолка». Весьма немногим женщинам удается достичь вершины корпоративного мира, лишь 32 женщины входят в состав управленческой верхушки 500 крупнейших промышленных компаний США (Доклад Генерального директора, 2018).

«Серьезным препятствием карьерного роста женщины является факт межгрупповой конкуренции. Он особенно обостряется в тех местах социального пространства, где социальная группа женщин проникает на территорию традиционной жизнедеятельности социальной группы мужчин и действует механизм сдерживания женской конкуренции. Женщины дают ей наименование «мужской солидарности» 
или «мужского шовинизма» (Уварова, Мясина, 2007). Эта ситуация не отвечает перспективам современного мирового развития, тем более что, согласно данным Всемирного банка, ликвидация дискриминации в отношении женщин на исполнительских и руководящих постах может повысить производительность труда на одного занятого на величину от 25\% до 40\% (Саммит «Женщины и экономика», 2021).

Следует подчеркнуть, что положение женщин в современной политике и экономике еще далеко от гармоничного баланса с положением мужчин, поэтому необходимо наполнять реальным содержанием понятие равных прав и возможностей мужчин и женщин в публичном мире и создавать условия для изменения гендерного контракта в сторону «равного статуса». Как отмечает западная исследовательница К. Фатторе, даже в рамках международных организаций исследователей международных отношений ситуация далека от гендерного паритета. Так, в ходе опросов было выяснено, что за 10 лет с 2006 года положение улучшилось, однако есть проблемы. Например, исследование 2015 года выявило сохраняющуюся озабоченность по поводу напряженности между семейными обязанностями и академической средой, структурную дискриминацию, а также ситуацию «обратной дискриминации» в отношении мужчин (Fattore, 2019).

Таким образом, приведенные гендерные исследования свидетельствуют о том, что в системе международных организаций для женщин сохраняется проблема гендерного неравенства в сфере трудоустройства и продвижения по карьерной лестнице. В тоже время стало очевидным фактом, что в системе университетского образования наметилась устойчивая тенденция к феминизации, в частности в тех областях, где готовятся специалисты для международных организаций и дипломатии. Это стало характерным явлением для российских университетов, которые готовят специалистов-международников. Следовательно, можно выделить следующий комплекс возникающих проблем. Во-первых, это «ножницы» между спросом и предложением, потому что во внешнеполитические ведомства и международные организации активно берут выпускников-юношей, но не девушек. Международные отношения и внешняя политика вообще представляют собой одну из наиболее консервативных сфер, так как речь идет о сохранении 
стабильности международной системы в целом. Ключевые понятия международных отношений, такие как власть, суверенитет, автономия, анархия, безопасность, и основные единицы анализа, такие как мужчины, государство и международная система, являются неотделимыми от патриархального разделения публичного/общественного и частного/ приватного. Они идентифицированы с мужским опытом и формами знания в публичной сфере, где доминируют мужчины в противоположность частной сфере, исторически определенной для женщин (Tickner, 1992). Впрочем, следует отметить, что руководство России формально поощряет расширение участия женщин в дипломатии. В.В. Путин, выступая перед российскими дипломатами, отметил: «По-прежнему в подборе дипломатических кадров незаслуженно слабое внимание уделяется женщинам. (...) Между тем, не номенклатурный отбор «по старинке», а сама современная действительность успела вырастить в России немалое число квалифицированных женщин-госслужащих. И надо понимать, что отсутствие (в отличие от многих других стран) так называемого «слабого» пола в российской дипломатии может стать слабым местом нашей внешнеполитической службы» (Выступление Президента Российской Федерации, 12 июля 2002). Сегодня девушки составляют примерно треть выпускников вузов, участвующих в конкурсе, ежегодно проводимом кадровой службой Министерства иностранных дел (МИД). В результате доля женщин среди дипломатов поднялась в последние годы до 15\%. Однако многие пришедшие на работу в МИД девушки отмечают недоверчивое к ним отношение и явное предпочтение в продвижении по служебной лестнице мужского персонала.

Во-вторых, профессиональные преференции для студентов-юношей создают напряженные межличностные отношения в студенческих группах. Поэтому для университетов необходимо разработать соответствующие перспективные планы по расширению спектра потенциальных рабочих мест для выпускников университетов, а также для достижения гендерной толерантности студентов нужно в системе подготовки, в частности специалиста-международника, реформировать многие устоявшиеся подходы.

Инновационная составляющая личностного и профессионального становления будущего специалиста является важнейшей в условиях 
современной «прорывной» идеологии развития российского государства в условиях «цифровой революции». Как отмечает российский исследователь Л.В.Абдалина, в студенте необходимо развивать стремление к преобразованиям, изменениям в мире вещей, людей, явлений. Важно сориентировать на личностную активность в освоении новых форм обучения: разработка авторских проектов, подготовка самостоятельных научно-исследовательских работ, участие в конкурсных программах и т.д. (Абдалина, 2013). Сегодня как никогда повышается значение таких качеств выпускника, как организованность, умение работать в команде, проведение научно-исследовательской деятельности по проблеме, выполнение профессиональных стандартов и т. п.

Как отмечает западный эксперт в области образования К. Сомервилль, современное поколение студентов должно не только руководствоваться в своих исследовательских проектах и выпускных работах узко профессиональными проблемами, но и воспитывать в себе гендерную культуру, что означает понимание культурной, политической, исторической и экономической значимости гендерного паритета в перспективе реализации Целей Устойчивого Развития до 2030 года (OOH) (Somerville, 2017, 21 October).

Для будущего специалиста-международника очень важна активность в публичной сфере - участие в дискуссионных клубах, молодежных объединениях, волонтерских группах. Так, например, проведение в нашей стране крупных международных форумов, спортивных мероприятий сопряжено с необходимостью решения сложных логистических задач, где студенты-волонтеры оказывают профессионально ориентированную помощь (знание языков, гендерная культура общения и пр.). Данная практика студенческой политической активности может способствовать и становлению политической карьеры, чему многочисленные примеры можно найти в биографиях западных политиков и дипломатов (Погодин, 2013).

Актуальная и социально-востребованная научно-образовательная и практическая задача, стоящая перед системой высшего образования страны - совершенствование профессиональной подготовки специалистов-международников и обеспечение ее кардинально нового качественного уровня. Для исследования вопроса о влиянии различных 
факторов на подготовку специалистов в сфере международных отношений и на их реализацию в профессиональной деятельности представляется уместным рассмотрение вопроса о стратегиях получения высшего образования мужчинами и женщинами. Как отмечается в Докладе рабочей группы ООН, в последние годы отчетливо обозначились различия в стратегии получения общего образования и подготовки к профессиональной деятельности мужчин и женщин. Так, женщины склонны к приобретению полного общего образования в рамках общеобразовательных школ, а в профессиональной подготовке все чаще ориентируются на получение образования более высокого уровня. Все более характерной для мужчин становится иная стратегия получения образования: в общеобразовательной школе - приобретение неполного общего образования, а затем учеба в системе начального и среднего профессионального образования (Гендерное равенство, 2005). Возможно, что данная тенденция в получении образования сказывается и в Российской Федерации, так как молодые люди чаще идут получать профессиональное среднее образование с последующим трудоустройством, а девушки стремятся, закончив полный цикл образования в школе, поступить в университет.

Рассмотрим, как данная тенденция конкретно проявляется в Высшей школе международных отношений Гуманитарного института Политехнического университета Петра Великого (Санкт-Петербург), где выпускают специалистов в области зарубежного регионоведения. Студенты получают знания по дипломатии, регионоведению, мировой политике, мировой экономике, международной торговле и сотрудничеству, международному публичному, частному и финансовому праву, политологии, государственному и муниципальному управлению, журналистике, связям с общественностью. По выпуску 2020 года доля девушек составляет $87 \%$, то есть количество девушек-студенток превышает количество юношей в 4 раза. Подобные тенденции наблюдаются практически во всех вузах России. По мнению Ю.Н. Коджаровой, ценностные ориентации студентов на различные сферы деятельности глубоко детерминированы гендерными характеристиками студенчества, в силу чего уже в вузе закладывается гендерная асимметрия различных сфер деятельности и отраслей экономики. Качественная 
трансформация системы международных отношений, вступление ее в глобализационную фазу развития требуют выработки принципиально нового видения и понимания происходящих в ней процессов. Превалирование «мужской» точки зрения, как в науке, так и в практике международных отношений является основным препятствием для выработки новых концепций и инструментов регулирования процессов, протекающих в мировой политике (Коджарова, 2011).

В последние годы в международном научном сообществе не утихают споры о действенности механизмов превентивной дипломатии ООН. Известно, что именно дипломатические методы включают в себя многофакторные сложные и длительные переговоры с целью уйти от силовых методов решения международных проблем. Как отмечает российский исследователь Т.В.Зонова, в психологической литературе часто встречается утверждение о том, что именно женщины обладают качествами, способствующими предотвращению конфликтов, снятию напряженности, урегулированию споров. Однако, как пишет далее Т.В. Зонова, конкретные примеры женщин, занимавших высокие посты в дипломатии, свидетельствуют об обратном, потому что жесткость, непримиримость, бескомпромиссность женщин-политиков объясняется тем, что, будучи в явном меньшинстве, женщины вынуждены постоянно доказывать свою «мужественность», право на пребывание на дипломатическом посту (Зонова, 2004). Таким образом, женщинам в сфере международных отношений сложно преодолевать сложившиеся веками стереотипы политического реализма, где на первый план выходит фактор силы. Поэтому понятие гендерного паритета, которое отстаивает руководство ООН, нуждается в наполнении реальным содержанием, когда ценностные ориентиры в международных отношениях будут определяться не борьбой за властное господство той или иной державы, а солидарным движением к мирному сосуществованию и устойчивому развитию.

\section{Выводы}

Нельзя не согласиться с мнением российского исследователя В.И. Михайленко о том, что хотя гендерные подходы в международных 
отношениях сравнительно молоды и имеют западное происхождение, «за ними большое будущее, поскольку они являются социально ориентированными» (Михайленко, 2020, с. 62).

В целом, подводя итоги, следует также отметить, что, во-первых, гендерные проблемы являются проблемами взаимоотношений мужчин и женщин в социально-экономической и политической сферах, а потому гендерные исследования не должны подменяться феминистскими теориями, потому что это разные предметные области. Во-вторых, феминизация университетской студенческой среды, особенно в сфере международной специализации, требует активной работы преподавателей и руководства по поиску новых сфер применения знаний молодых специалистов. В-третьих, сами студенты в стремлении к карьерному росту не должны замыкаться исключительно на государственных служебных структурах, а находить себе профессиональное применение в многообразной международной жизни (неправительственные организации, спортивные организации, народная дипломатия и пр.). Наконец, в-четвертых, развитие гендерной культуры в студенческой среде должно способствовать формированию объективных предпосылок для интеллектуального прорыва российской науки в условиях четвертой научно-технологической революции.

\section{ЗЕЙНАБ ЗЕЛИМХАНОВНА БАХТУРИДЗЕ}

д.полит.н., профессор Высшей школы международных отношений Гуманитарный институт Санкт-Петербургского политехнического университета Петра Великого

\section{НАТАЛИЯ АЛЕКСЕЕВНА ВАСИЛЬЕВА}

д.филос.н., профессор кафедры «Мировая политика» Санкт-Петербургский государственный университет 


\section{Ссылки}

Dai, W. (2012). Women! Embrace your inner geek. URL: http://edition.cnn.com /2012/03/07/business/weili-dai-women-geeks.

Egboh, E.A., Aniche, E.T. (2011). Feminization of international relations and internationalization of feminism: deconstructing mainstream international relations. URL: https://www.researchgate.net/publication/276141080_FEMINIZATION_OF_INTERNATIONAL_RELATIONS_AND_INTERNATIONALIZATION_OF_FEMINISM_DECONSTRUCTING_MAINSTREAM_INTERNATIONAL_RELATIONS.

Fattore, Ch. (2019). Nevertheless, She Persisted: Women's Experiences and Perceptions within the International Studies Association. International Studies Perspectives, 20(1), 46-62. URL: https://doi.org/10.1093/isp/eky006.

ISA: The International Studies Association (2021). URL: http://www.isanet.org/ (дата

Mertus, J. (2007). Teaching Gender in International Relations. International Studies Perspectives, 8(3), August, 323-325. URL: https://academic.oup.com/isp/ article-abstract/8/3/323/1803203?redirectedFrom=fulltext.

Ruddick, S. (1995). Maternal Thinking: Towards a Politics of Peace. Beacon Press. URL: https://archive.org/details/maternalthinking0000rudd/mode/2up.

Scott, J. (1986). Gender: A Useful Category of Historical Analysis. American Historical Review (New York), 91(5), 59-67.

Somerville, C. Opinion: The future of global development: 5 trends graduate students should know. (2017, 21 October). URL: https://www.devex.com/news/opinion-the-future-of-global-development-5-trends-graduate-students-should-know-91189.

Steans, J. (1998). Gender and International Relations: An Introduction. New Brunswick, N.J.: Rutgers University Press.

System-wide strategy on gender parity (2021). URL: http://www.unwomen.org/en/ how-we-work/gender-parity-in-the-united-nations.

Tickner, J.A. (1992). Gender in International Relations Feminist Perspectives on Achieving Global Security. New York: Columbia University Press.

Tickner, J.A., True, J. (2018). A Century of International Relations Feminism: From World War I Women's Peace Pragmatism to the Women, Peace and Security Agenda. International Studies Quarterly, 62(2), 1 June, 221-233. URL: https://www.researchgate.net/publication/321343644_A_Century_of_International_Relations_Feminism_From_World_War_One_Women's_Peace_Pragmatism_to_the_Women_Peace_and_Security_Agenda.

True, J. (2001). Feminism. W: S. Burchil, A. Linklater (eds.). Theories of International Relations. New York: Palgrave.

Абдалина, Л.В. (2013). Основные характеристики инновационного потенциала личности современного специалиста. Вестник Воронежского государственного технического университета. URL: file://C:/Users/Dns/Downloads/osnovnye-harakteristiki-innovatsionnogo-potentsiala-lichnosti-sovremennogo-spetsialista. pdf.

Агамова, Н.С., Аллахвердян, А.Г. (2021). Российские женщины в науке и высшей школе: историко-научные и науковедческие аспекты (к 150-летию со дня 
рождения С. В. Ковалевской). URL: http://ihst.ru/projects/sohist/papers/ag-al01v. htm.

Виноградова, С.М., Дунаева, Ю.Г., Зиатдинов, Д.Ф. (2017). Женщины, наука, образование: у истоков гендерных исследований международных отношений. Вестник СПбГУ. Политология. Международные отночения, 10/3, 260-268. URL: https://dspace.spbu.ru/bitstream/11701/8594/1/06-Vinogradova.pdf.

Виноградова, С.М., Васильева, Н.А. (2013). Пространство и время в гендерном измерении. Вестник СПбГУ, 6(4), 110-117.

Выступление Президента Российской Федерации В.В. Путина на расширенном совещании в Министерстве иностранных дел с участием глав дипломатических миссий за рубежом 12 июля 2002 года. (2002). URL: http:// www.kremlin.ru/events/president/transcripts/21674.

Гендерное равенство и расширение прав и возможностей женщин в России в контексте иелей развития тысячелетия (2005). URL: http://www.undp.ru/ Gender_MDG_rus.pdf.

Доклад Генерального директора. Инициатива, касающаяся трудящихся-женщин: импульс к обеспечению равенства Международная конференция труда, 107я сессия (2018). URL:https://www.ilo.org/wcmsp5/groups/public/---ed_norm/---relconf/documents/meetingdocument/wcms_630128.pdf.

Здравомыслова, Е.А., Темкина, А.А. (1999). Исследования женщин и гендерные исследования на Западе и в России. Релевантность западных теорий для анализа российского гендера. Общественные науки и современность, 6, 177185. URL: https://ecsocman.hse.ru/data/749/122/1218/017yDRAWOMYSLOWA. pdf.

Зонова, Т.В. (2004). Новые проблемы дипломатии. W: А.В. Торкунов (ред.). Современные международные отношения и мировая политика. Москва: Просвещение, 467-494.

К обществам знания: Всемирный доклад ЮНЕСКО (2005). Париж: ЮНЕСКО. URL: http://unesdoc.unesco.org/images/0014/001418/141843r.pdf.

Коджарова, Ю.Н. (2011). Гендерные аспекты современного образования в сфере международных отношений. Вестник МГИМО Университета, 202-206. URL: https://cyberleninka.ru/article/n/gendernye-aspekty-sovremennogo-obrazovaniya-v-sfere-mezhdunarodnyh-otnosheniy.

Лысова, И.И. (2009). Формирование гендерной культуры будущего специалиста в образовательном процессе ВУЗа. Белгород. URL: https://www.dissercat. $\mathrm{com} /$ content/formirovanie-gendernoi-kultury-budushchego-spetsialista -v- obrazovatelnom-protsesse-vuza/read.

Михайленко, В.И. (2020). Эвристический потенциал гендерных теоретических подходов в исследовании международных отношений. История и современное мировоззрение, 4, 55-62, DOI: 10.33693/2658-4654-2020-2-4-55-62.

Новаторские решения в области измерения неравенства и бедности. URL: http:// hdr.undp.org/en/media/HDR_2010_RU_Chapter5_reprint.pdf.

Ответственность за достижение фактического равенства женщин и девочек: круглый стол министров ЭКОСОС (2015). URL: http://www.unwomen.org/en/ csw. 
Погодин, С.Н. (2013). Women in the Political Life of Finland. W: S. Pogodin, A. Lindeman, S. Lehto-Kylmanen, O. Bulavenko (eds.). Investigations in social sciences and humanities: science digest. Sankt Petersburg: Publishing House of Polytechnical University, 172-178.URL: https://elibrary.ru/download/elibrary_22637879_33966348. pdf.

Саммит «Женщины и экономика» (2021). URL: http://womenofrussia.org/ international.aspx? $\mathrm{Id}=282$.

Уварова, В.И., Мясина, Е.П. (2007). Женский интеллектуальный капитал в российском инжиниринге. W: А.В. Безгодова, В.В. Смирнова (ред.). Интеллектуальный капитал - основа опережающих инноваций: монография. Санкт-Путербург: НЦ «Планетарный проект», Орел: ОрелГТУ.

Федеральный закон от 29.12.2012 N 273-Ф3 (ред. от 27.06.2018) „Об образовании в Российской Федерации” (2012). URL: https://fakon.ru/laws/ federalnyy-zakon-ot-29.12.2012-n-273-fz/.

Шестопал, Е.Б. (2002). Политическая психология: учебник для вузов. Москва: ИНФРА-М. 